\title{
A note on monetary policy with interest-rate contingent claims as indicators
}

\author{
Thierry Roncalli* \\ FERC, City University Business School, England
}

January 13, 1999

\begin{abstract}
In this paper, we consider the use of interest rate contingent claims as indicators for the monetary policy. We analyze two approaches: one based on the term structure of zero bonds and another based on interest-rate option derivatives. We show how traditional tools based on the Black framework could be biased to build indicators for monetary policy. In fact, the second method could not be viewed as an alternative approach, but as a complementary approach of the term structure approach.
\end{abstract}

\section{Introduction}

The conduct of monetary policy by central banks could be achieved by using some targets and instruments. By doing that, they need to build indicators. In most case, these indicators are based on interest rates expectations. Two main methods are available to compute these expactations. The first one is to consider the term structure of zero bonds (or interest rates). The second one is more complex and is based on derivatives. Contingent claims could be useful to extract expectations because these assets look forward. In this short note, we present briefly these two approaches and we illustrate the fact that these two approaches are not competitive but complementary. Moreover, the particularity of interest rate contingent claims imply that we have to imagine new specific tools for the second approach.

\section{Monetary policy with term structure of zero bonds as indicators}

The term structure of zero bonds can be used to determine the yield curve and the term structure of forward interest rates. These forward rates can be used as indicators, which contain some informations on interest rates market expectations (Svensson [1994]). So, they can be used to forecast interest rates and we can forecast foreign exchange rates (under the assumption of uncovered interest rates parity) or inflation (under the assumption of Fisher relationship). They have even been used to estimate the credibility of EMU.

\section{Monetary policy with interest rate options as indicators}

At the beginning of the nineties, a number of works appear that use fixed-income derivative prices to extract expectations. In most cases, the observed prices are compared with the implications of theoretical model. Biases are imputable to the behaviour of agents. This is the case of skweness premia or risk neutral density. In other cases, the theoretical model is used to estimate some parameters from the observed data. This is the case of implied volatility or jump and smile curve. These tools are also used to quantify the expectations of the market. An example of such analysis could be found in BAHRA [1996].

*email: t.roncalli@city.ac.uk 
The following example is taken from GAMAs [1997]. The data are provided by MATIF S.A. and correspond to options on Pibor 3 months interest rates. We perform an estimation of the risk neutral density by using the method suggested by BAHRA [1996] based on a mixture of two log-normal densities. We consider two observed dates (29 and 30 july 1993) and two maturity dates for the options (september and december 1993). The period is important because the market was expected about a fall of German interest rates. After the reunion of its monetary committee, the BundesBank announces a very small decrease for the Lombard rate and nothing for the discount rate. The market is very disappointed. It anticipates that interest rates will fall too, but just for a very short period (see Figure 2).

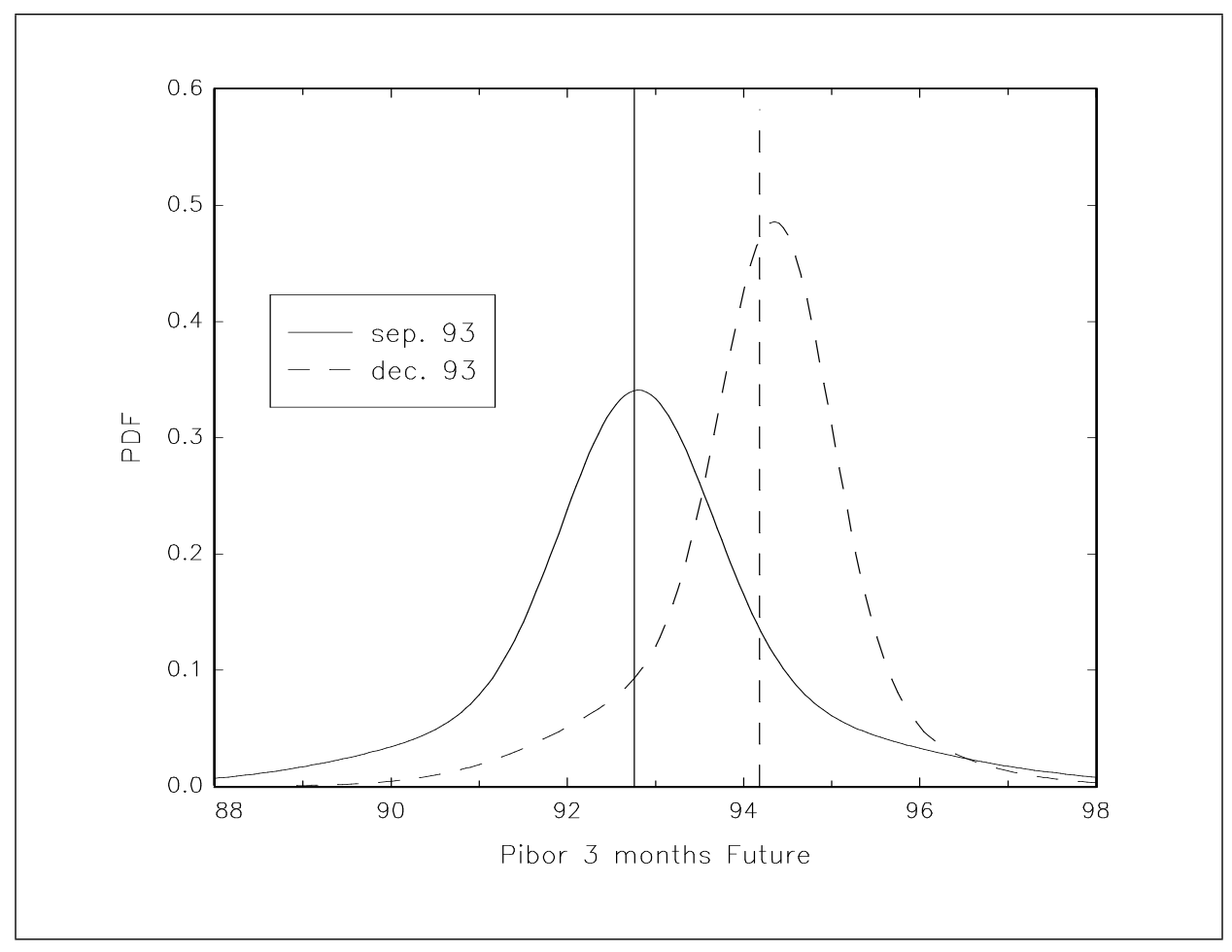

Figure 1: Risk neutral density function estimation (29/07/1993)

\section{Term structure and interest rate derivatives}

The example presented above is based in fact on Black's framework. The model is old, but during a long time, it was the only model to compute the contingent claims price on interest rates. In 1996, Ho and Lee publish a seminal paper. They show how observed term structure could be used to compute interest rate derivatives. Even if the Black model is still used, new models who depend on observed term structure are becoming widespread. These models are for example Heath-Jarrow-Morton or Black-Derman-Toy or the trinomial model of Hull and White. With these models, the term structure influences the derivatives prices because it is an input of these models. In the case of HJM, we need the forward rates to compute the prices of interest rate contingent claims. For BDT, both the term structure of interest rates and volatilies are required. The HW model need in input the term structure of interest rates. So, there is an influence of the observed term structure on the theoretical option prices, and so on the market option prices. This imply that expectations in the bond market may have an influence on the expectations in the option market.

We report in Figure 3 the option prices for an interest rate contingent claim computed by the Black and Hull-White model. The contingent claim is defined by $P(t)=100(1-r(t))$ where $r(t)$ is the instantaneous interest rate. The actual price is 90. We consider an option on this contingent claim with maturity half a 


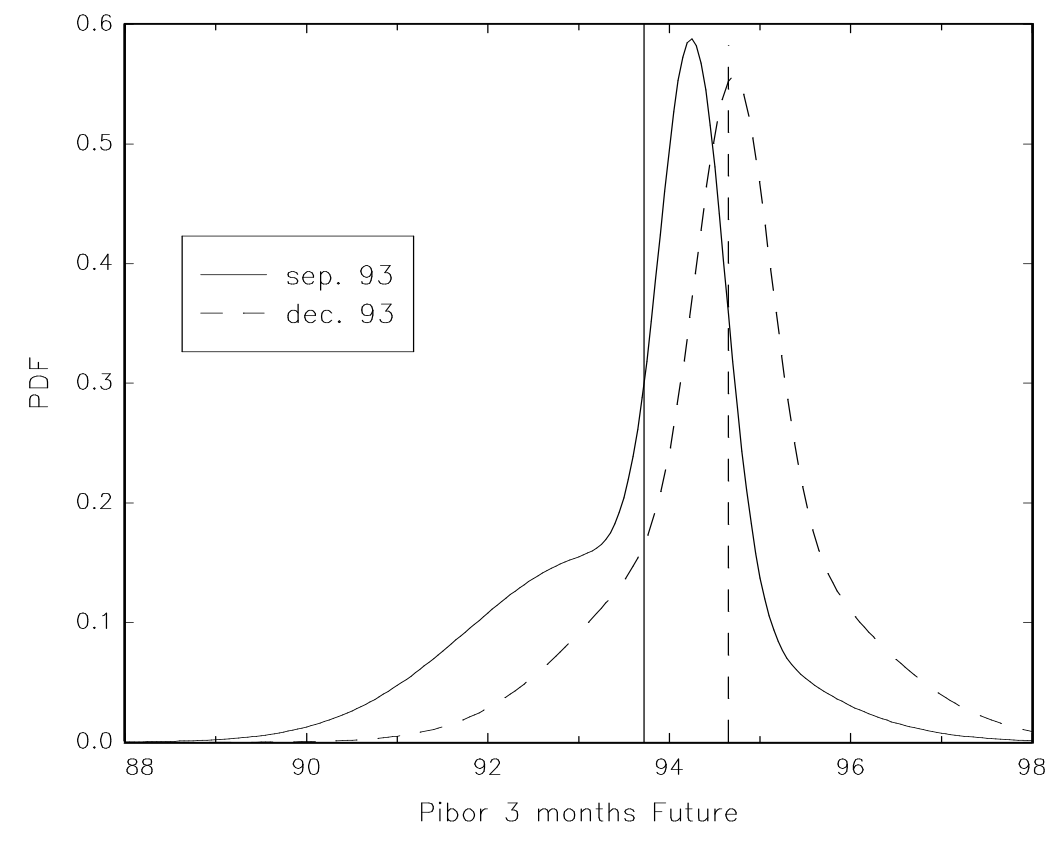

Figure 2: Risk neutral density function estimation (30/07/1993)

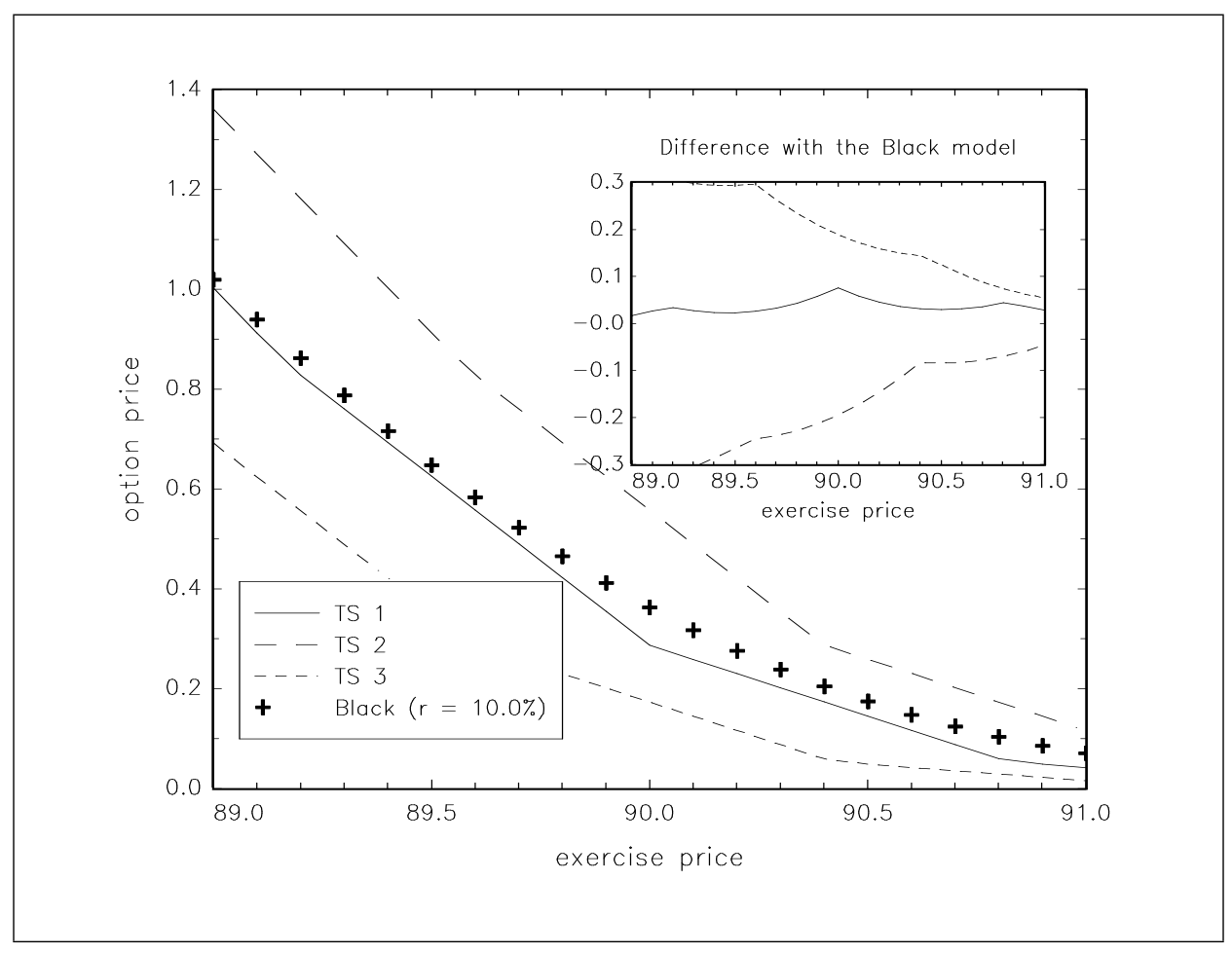

Figure 3: Influence of the term structure on interest rate options 
year. We suppose that the volatility of $P(t)$ is $1.5 \%$. We evaluate this option for different values of exercise price and for three term structure of interest rate:

\begin{tabular}{c|ccc} 
Maturity (in months) & TS1 & TS2 & TS3 \\
\hline 1 & $10 \%$ & $10 \%$ & $10 \%$ \\
2 & $10 \%$ & $9.95 \%$ & $10.05 \%$ \\
3 & $10 \%$ & $9.90 \%$ & $10.10 \%$ \\
4 & $10 \%$ & $9.85 \%$ & $10.15 \%$ \\
5 & $10 \%$ & $9.80 \%$ & $10.20 \%$
\end{tabular}

Of course, the term structure has no influence on option prices computed with the Black model. We notice that these option prices are in fact very close to these obtained with the Hull-White model when the term structure is flat. But the prices are very different with the other yield curves.

\section{Implications for the construction of indicators based on interest rate options}

In many case, indicators based on interest rate options are built in a Black framework. These tools may give some strange results if the pricing process is based on an interest rate model. Interest rate models take into account the information contained in the term structure, not the Black model. That's why we may observe some phenomenas that could in fact be explained by the term structure. For example, if we use the Black model to compute skewness premia or implied volatility, some biaises could appear. And some shifts in the RND curve could be explained by the position of term structure. Indeed, these phenomena are coherent with the information contained in the term structure. But the most important thing is to note that the information revealed by the option are in this case the same information given by the term structure.

If we use the option prices obtained above with the Hull-White model, and if we compute the implied volatilities with the Black model, smile effects appears (Figure 4). It would be the same thing with Skewness premia. Now, if we estimate the risk neutral density with a mixture of two log-normals, we remark that the density shifts to the right when the term structure is decreasing. If we would extract expectation informations, we would say that the market expected that the price of the contingent claim will increase, so that the interest rate will decrease. The problem is that the term structure contains this information before. So, this is not a new information. The information in the option market is in fact the same as this in the bond market, but it is coded differently.

Figures 6 and 7 present estimation of risk neutral density and term structure of interest rates for the dates of 28 and 30 march 1995. Theses two graphics are very interesting, because for one date, information provided by the option market is coherent with these given by the bond market and for the other date, the informations are in conflict. On 28 march 1995, we see that the market expect that the Pibor 3 months future will increase, that is the interest rates will decrease. These information is not confirmed by the shape of the yield curve. Two days after, we observe an inversion of the term structure. For this date, both the option market and the bond market are waiting for a decreasing of interest rates.

\section{Conclusion}

This short note shows that information derived from interest option prices and tools based on Black framework is difficult to interpret. This information may in fact be a mixture of the information in the bond market and another information that is specific to the option market. In the case when the two types of information are coherent, there is no problem. We could say that the option market confirm the information in bond market. The problem is when the two types of information are different.

A prolongation of this note is of course to build tools based on interest rate models framework, like Hull-White or Black-Derman-Toy. For example, we could estimate implied volatility in a better way. Or we could estimate implied term structure to compare it to observed term structure. 


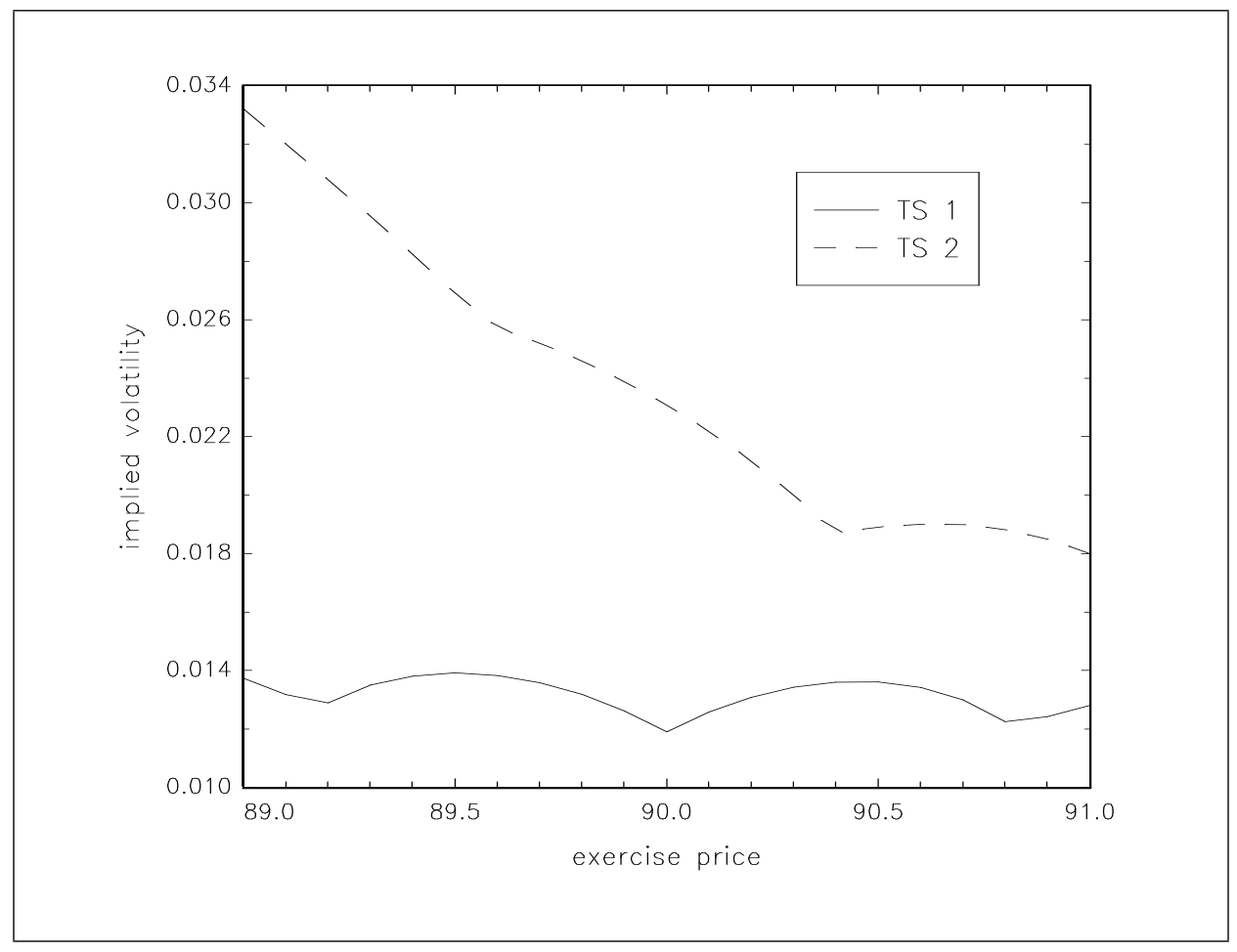

Figure 4: Implied volatilities based on Black model

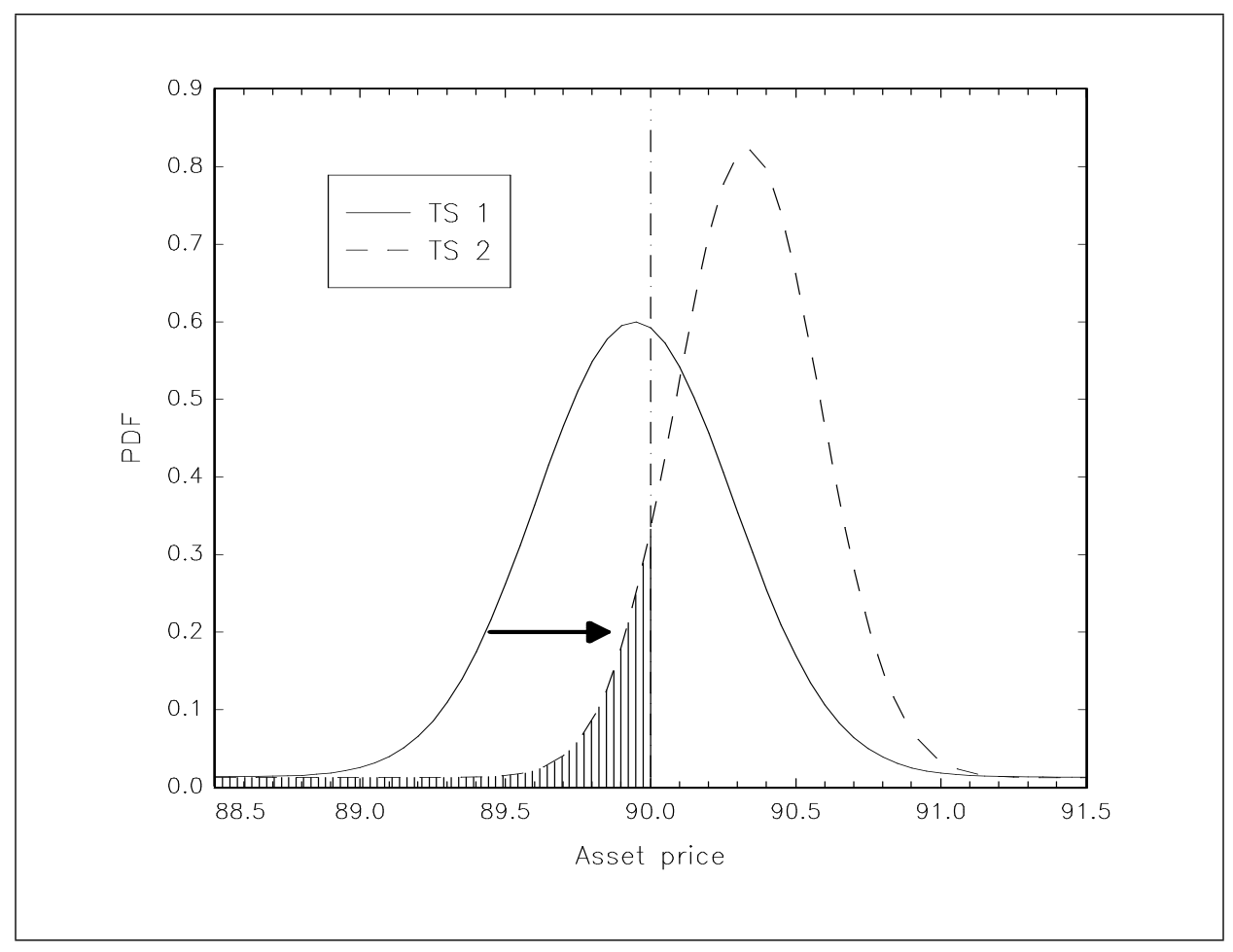

Figure 5: Risk neutral density estimation 


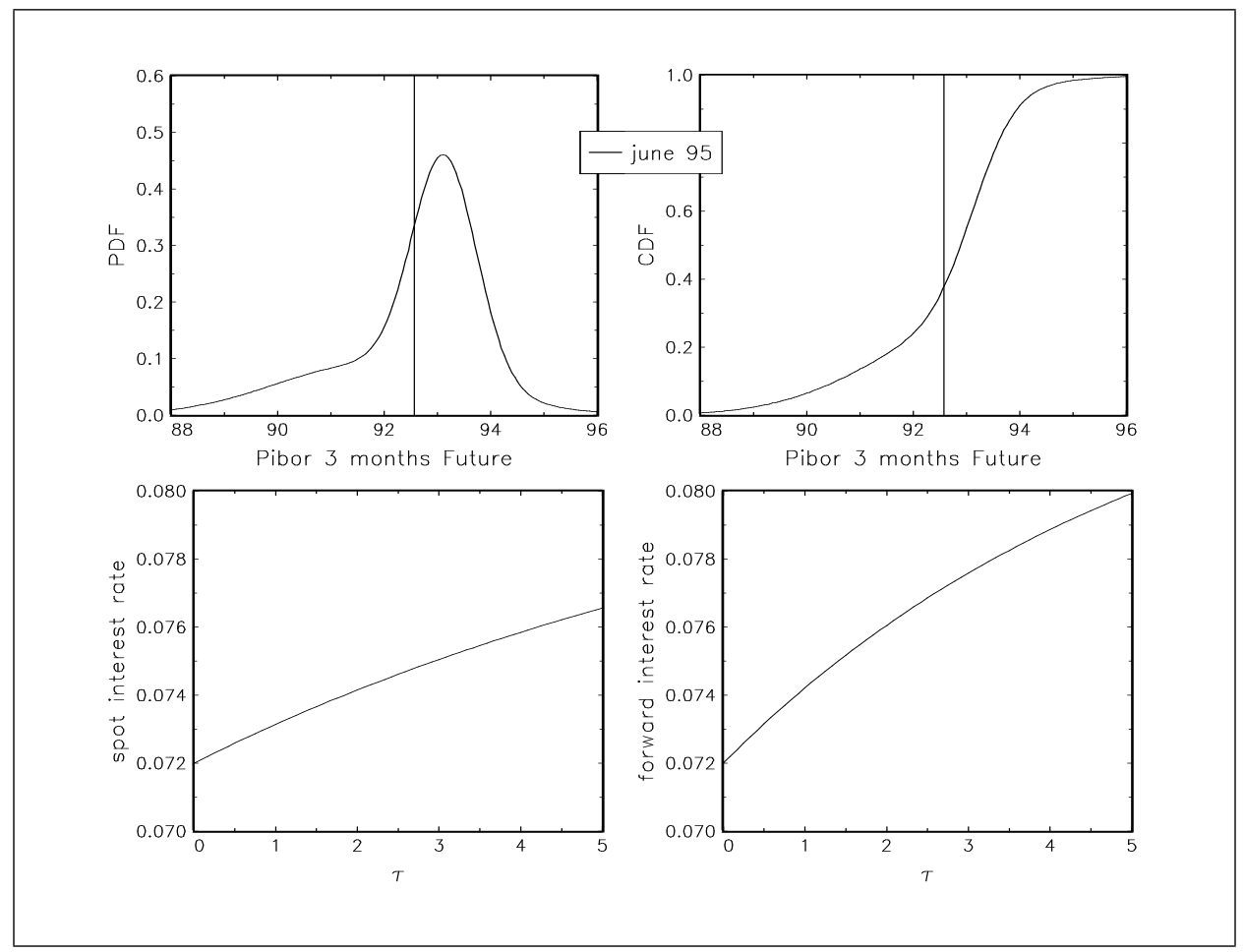

Figure 6: RND estimation and term structure of spot and instantaneous forward interest rates (28/03/1995)

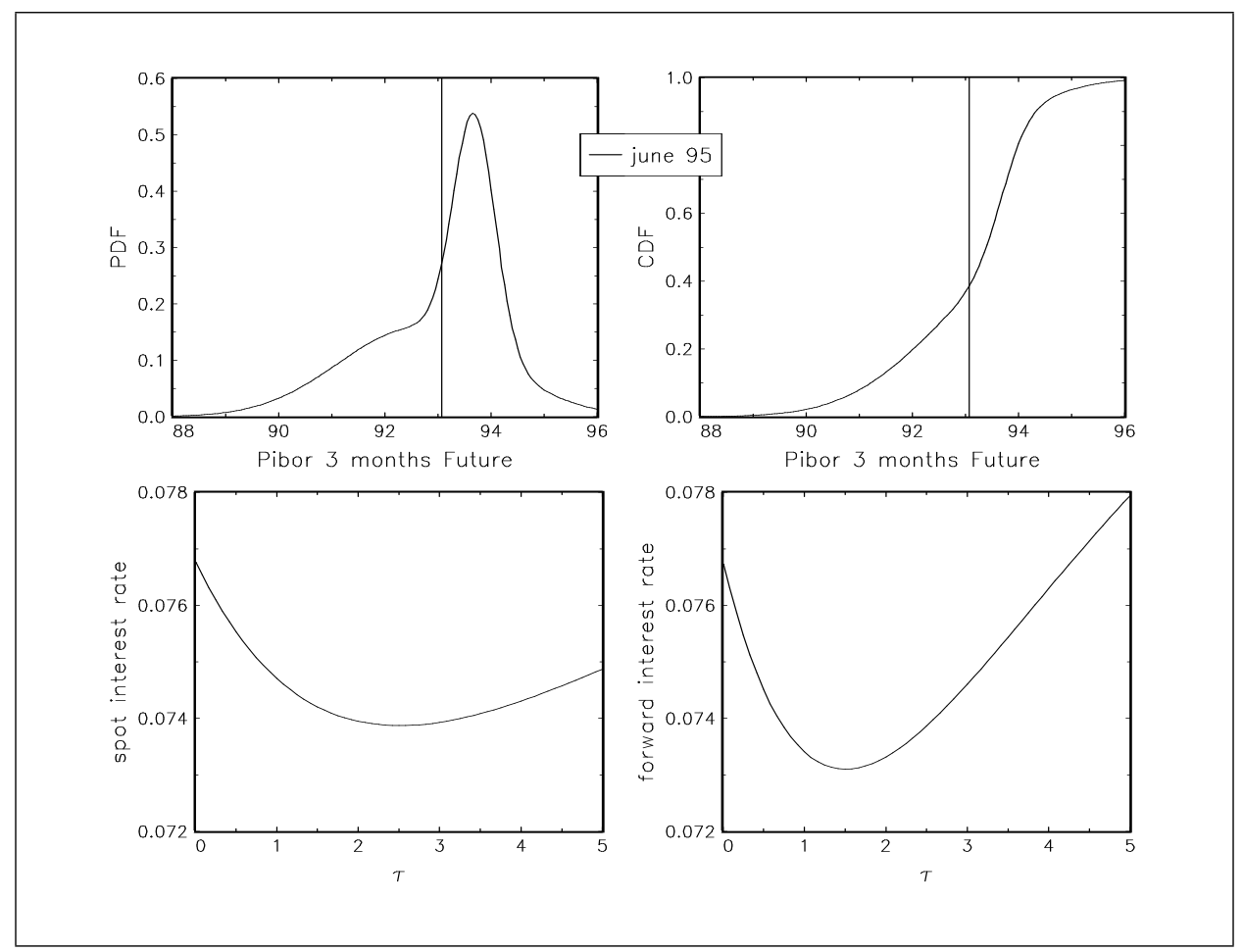

Figure 7: RND estimation and term structure of spot and instantaneous forward interest rates (30/03/1995) 
The implication of this note is very obvious. We could of course build indicators based on interest rate contingent claims, but this approach could not completely remplace the first appraoch, because if we would like to use interest rates options, we have to refer to the term structure.

\section{References}

[1] Bahra, B. [1996], Probability distributions of future asset prices implied by option prices, Bank of England Quarterly Bulletin, 299-311, August

[2] Black, F. [1976], The pricing of commodity contracts, Journal of Financial Economics, 3, 167-179

[3] Gamas, M-N. [1997], Extraction d'informations du marché des options par une banque centrale : application au marché monétaire français, LARE Working Paper, Université Montesquieu-Bordeaux IV

[4] Hull, J. and A. White [1993], One-factor interest-rate models and the valuation of interest-rate derivative securities, Journal of Financial and Quantitative Analysis, 28, 235-254

[5] Svensson, L.E.O. [1994], Monetary policy with flexibles exchange rates and forward interest rates as indicators, Cahiers économiques et monétaires de la Banque de France, 43, 305-332 